Skepticism, Dordrecht, Reidel, 1983 y, desde dentro del tessmo, Gutting, G.: Religious Belief and Rehigious Skepticism, Notre Dame U.P., 1982; Ouinn, P.: "In Search of the Foundations of Theism", Faith and Phitosophy, 2 (1985); Audi, R.; «Direct Justification, Evidential Dependence, and Theistic Belief*, en la antología de la que cos coeditor; $y$ Pojman, L.I.: Retigious Behef and the Will, Lon. dtes, Routledge \& K.P. 1989. Aparte de las obras de Swinburne (1982) y Phillips (1988).

46. De entre su vasta obra destacan Faith and Krowledge, Ithaca, Comell U.P., 1957. Evil and the God of Love, Londres, Macmillan, 1966, Death and Eternal Life (ídem), y An Interpretation of Religion, Londres, Macmillan, 1989, en donde ofrece una visión global de las religiones bajo todos sus aspextos. Especificamente sobre el pluralismo re. ligioso son sus God and the Universe of Faiths, Nueva York, St. Martin, 1973 y Problems of Religious Pluralisin, Londres, Macmillan, 1985. Es asimismo editor o coxditor de muchas obras sobre el tema.

47. En la medida en que se pretenda hacer solo teología filosoffica (o Philosophy of Christian Retigion. como a veces se denomina), esto no es un defecto. Pero sí lo es para hacer filosofla de la religion, "uberhaupts.

48. Por contra, los autores no anglosajones de los siglos $\mathrm{XTX}$ y $\mathrm{xX}$-salvo Kierkegaand y Wittgenstein- son olínpicamente ignorados.

49. Como muestra, Morris, T: The Logic of God Incamate, Ithaca, Cornell U.P., 1986 -donde se aplican la filosofia de la mente y la semantica sobre la identidad para resolver el problema de las "dos naturalezas" de Cristo-. Y los colectivos: Mornis, T. (ed.): Philosophy and the Christian Faith, Notre Dame U.P., 1988; Feenstra, R.J. \& Plantinga Jr., C. (eds.): Trinity, Incamation and
Atonenent (idem 1989); y Flint, T. (ed.): Christian Philosophy, (Gdem 1990).

50. Revista de Filosoffa (Madrid). XXV (1966), pp. 291-366.

51. Publicados respectivamente en Barcelona, Aricl, 1977; Madrid, Mañana, 1978; Salamanca, Sigueme, 1978; y Madrid, Mondadori, 1989.

52. Madrid, Revista de Occidente, 1970 y 1973 - -el segundo, en colaboración con J. Martín Velasco-

53. Madtid, Encuentro, 1989. Refiriéndose a la precariedad de nuestra corriente en España, afirma: "Sólo España ha llegado a ser tan "moderna" en filosofia, que no sabe nada de su presente por ignorar su pasado: ¿Por qué los ayer neopositivis tas y analíticos a remolque no dan cuenta hoy, aunque sea de nuevo a remolque, de esta tradición operativa en la actualidad? (p. 343). Justa, pero unilateral, queja, a la que habria que añadir: cor qué los filosófos de la religión españoles "pasan" alegremente de la filosofía analítica?

54. Ouito, Ediciones de la Universidad Católica, 1981.

55. Además de las citadas a lo largo de las notas: Bochenski, J.M.: La logica de la religion :Buenos Aires, Paidós, 1967; Macquarrie, J.: Godtalk. El anatisis del lengtaje y la logica de la teologia, Salamanca, Sigueme, 1976; Varios: Filosofia de ia ciencia y religión, Salamanca, Sígueme, 1976; Albert, H.: La miseria de la teologia, Barcelona, Alfa, 1982: y Kolakowski, L.: Si Dios no existe, Madrid, Tecnos, 1985. Todos son valiosos aunque, curiosamente, ninguno es un aflósofo analítico de la religión*. Para tratar de rellenar esta laguna filosófica estamos traduciendo actualmente una docena larga de entre los artículos más representativos en nuestro campo.

\title{
Individuos e información: sobre el marxismo analítico
}

\author{
J. FRANCISCO ÁLVAREZ \\ UNED Madrid
}

Hace ocho años que Jon Elster desde las páginas de London Review of Books, en el artículo "Cien años de ciencia social marxista», recordaba un aforismo de Alfred North Whitehead: «Una ciencia que se resiste a dudar de sus fundadores y a olvidarlos está perdidan. ${ }^{1}$ Allí Elster señalaba sus particulares objeti- 
vos en la investigación social de inspiración marxista: "lo que pretendo es conseguir que el marxismo (o al menos sus partes valiosas) se sumerja en la corriente principal de la ciencia social y que pierda su identidad como una corriente separadas.

Esa misma referencia a Whitehead podemos encontrarla en el libro de J. Roemer, Free to Lose. ${ }^{2}$ En esta última ocasión Roemer anade que, en buena medida, lo que ha ocurrido con el marxismo y la investigación en ciencias sociales es que ciertas partes del marxismo han sido refutadas decisivamente mientras que otras aportaciones suyas han quedado incorporadas a la estructura común compartida por todos los cientificos sociales.

Pero ocurre, según Roemer, que todavia quedan ciertos elementos valiosos e importantes que no son apreciados fuera del campo marxista y que a veces tampoco son reconocidos desde su interior. Esos elementos valiosos, que parece querer defender Roemer, no son fácilmente identificables; bien pudiera ser que parte del giro que piensa producir en el seno de la investigación marxista refleje una limitación del programa de investigación marxiano $y$ que, a la vez, sea una simple aceptación del programa de la ciencia social académica. $^{3}$

En esa perspectiva señalada por dos de sus principales promotores es en la que cabe situar el trabajo del maxismo analítico: se le puede entender como un programa actual para las ciencias sociales, un programa sin pretensión de exclusividad que intenta ser una contribución a la línea central de la investigación en ciencias sociales, tanto desde el punto de vista substantivo de la elaboración cientifica concreta como en aspectos generales metodológicos de esas ciencias.

Sin embargo, desde el principio, es preciso apuntar que algunas de las disputas producidas entre las orientaciones marxistas y las ciencias sociales academicamente establecidas puede que tengan difícil solución. Aunque alguna suerte de equilibrio epistemológico ecléctico quiera recoger la doble perspectiva, ocurre que el espacio conceptual cubierto por las ciencias sociales tiene mucho que ver con espacios de conformación práctica de nuestras creencias y aspiraciones; por tanto, ese espacio conceptual tendrá que ver con la política y con especiales influencias "externas" que aparecen en el filtraje de la zona de ese espacio que será sometida a investigación. Encontramos aquí una conexión no sólo en el ámbito de la teoría política sino en las políticas concretas y en sus orientaciones estratégicas; por ejemplo, buena parte de lo que se puede decir sobre economía política está determinado por las realizaciones económicas práctico-materiales; en muy pocos casos sucede al revés - excepto para alguna pretendida y abominable «dirección científica de la sociedad $n-$.

Aún así, y precisamente por el sesgo político de las ciencias sociales, no parece tener mucho sentido mantener posiciones de aislamiento local de la propia teoria; en la práctica se están dando fenómenos suficientemente explícitos de mezclas y combinaciones, que van desde la institucionalización socialdemócrata hasta las transformaciones político-económicas de las sociedades del socialismo real. Unas mezclas que producen nuevos problemas en esas sociedades y fuerzan, por tanto, al análisis del instrumental teórico con el que intentan intervenir los científicos sociales en esas nuevas estructuras políticas.

La mayor parte de las orientaciones que se reclaman herederas o pertenecientes a la tradición marxista, normalmente manifiestan una tendencia ex- 
presa a intervenir en el espacio académico de las ciencias sociales. La variada pretensión de ser una ciencia de las sociedades, una teoría de la revolución y una guía para la acción política, conforma entre los marxistas un vector dirigido a la intervención práctica y social, y, por ello, no es extraño que las versiones actuales del marxismo, aun tratándose de quienes proponen variantes sofisticadas, tengan principalmente la aspiración de constituir un programa para las ciencias sociales. Lo que ya no parecen procurar es la intervención en la vida política, algo que por otra parte no es sólo síntoma del tipo de marxismo que cultivan sino de cómo comparten el reflujo general de los intelectuales en relación con la participación y la responsabilidad social.

$\mathrm{Al}$ presentar los rasgos básicos de lo que se cmpicza a conocer estos ultimos años como marxismo analítico, lo haremos intentando hacer aflorar su propio provecto y su indudable pretensión de convertirse en un programa de investigación para las ciencias sociales.

No consideramos que el marxismo analítico sea ya un programa constituido, ni que represente líneas de investigación institucionalizadas $\mathrm{y}$ en marcha en las ciencias sociales contemporáneas. Más bien vamos a tratar de discutir sus propias aspiraciones, de qué manera se produce su incidencia en las ciencias sociales y cómo presentan su propuesta de atender a cuestiones no habituales ni en el marxismo ni en las ciencias sociales de hoy.

Los proponentes del marxismo analítico lo presentan más como un punto de vista en ciencia social que como un programa cerrado. A la vez señalan que tratan de fundamentar y esclarecer a partir de los resultados de la investigación en ciencias sociales algunas de las evaluaciones generales tradicionales en el marxismo.
Como son muchos los preconceptos y los prejuicios que se dan en torno al marxismo, y en el interior de las tradiciones marxistas, por lo que se refiere a sus plantcamicntos sobre la práctica cientifica en la ciencia social, si queremos avanzar hacia algún tema de interés tenemos que eliminar algunos pseudoproblemas, o al menos señalar algunas cosas que no nos van a interesar.

En primer lugar, la cuestión no está en que desde el marxismo analítico se señale algún «nuevo método», ni en que otra vez se ofrezca el "verdadero y auténtico" método marxiano nucleador de la investigación sociopolítica desarrollada por Marx. Ahora la cuestión consistc en tomarse en serio algunos tópicos de la tradición marxista referidos a la investigación social, pero teniendo en cuenta la transformación del utillaje científico producido en las ciencias sociales durante el último siglo. Sin duda esto les exigirá algunas veces pensar en y con términos de ciertos instrumentos formales como son la tcoría de juegos, la teoría de la decisión y el instrumental matemático de la economía neoclásica.

Si la cuestión dd método es el primer preconcepto a desechar, también antes de entrar definitivamente en el tema señalemos que no pretenderé aquí rcivindicar sin más el marxismo, ya sea el analítico o el hegelianizante; aunque como en ocasiones ha dicho $\mathrm{J}$. Muguerza: «Ahora que parece estar en descrédito, valdría la pena estudiarlo atentamente" ${ }^{4}$

Hace algunos años constituía un tópico la discusión entre análisis y marxismo, entre filosofía analítica y marxismo; no sicmpre esa confrontación tenía los tonos del debate académico y con excesiva facilidad se utilizaba el argumentum ad hominem. En España, al estar ambas tendencias poco institucionalizadas, se producía, sin embargo, 
cierta común defensa intercatecúmenos; tenía la discusión cierto aire de familia con otros encuentros; por ejemplo, con el intento de diálogo entre cristianismo y marxismo, aunque este último debate tenía mayores condicionamientos políticos. Nos parecia asistir a un intento de superación del estrecho marco de dos ámbitos y tradiciones intelectuales, y, tal como se pretendía en 1974 desde Revista de Occidente, en el número "Análisis y dialéctica", ${ }^{5}$ era posible tratar de "tender puentes" no irenistas entre las dos tradiciones. Si cl ejemplo tradicional del marxista para el analítico era Federico Engels trepando por el árbol de la ciencia con el detector de contradicciones en bandolera (con acertada imagen propuesta en aquella ocasión por Alfredo Deaño), el ejemplo de analítico para el marxista era el profesor despistado analizando si se podía calificar de moral el acto de devolver los libros en préstamo. Desde luego no proponemos a estos dos personajes como ancestros del marxismo analítico, o al menos no creo que los aceptaran sin más sus cultivadores.

La denominación «marxismo analíticon es reciente; con ella se hace referencia a una nueva tendencia que está adquiriendo en teoría social carta de naturaleza con intentos varios de institucionalización académica. Como recuerda John Roemer en su introducción a una compilación de textos, publicada precisamente con el título de Analytical Marxism: "... lo que ahora aparece como una nueva variedad en teoria social se ha ido conformando en la pasada década: el marxismo analíticamente sofisticado. Sus cultivadores están muy influenciados por cuestiones marxianas que ahora abordan con el instrumental contemporáneo de la lógica, las matemáticas y la construcción de modelos. Su postura metodológica es convencional; de manera consciente estos autores se presentan como el resultado conjunto de tradiciones marxistas y no marxistas". 6

Por tanto, vemos que, al menos explicitamente, no se trata solo de la influencia de la filosofía analítica sobre el marxismo. Según los autores, unos estăn más influidos por la filosofía analítica, como es el caso de Gerald Cohen, y otros por las líneas dominantes en la investigación en ciencias sociales (tal es el caso de la influencia de la economía matemática sobre Roemer). El ámbito cs plural; se puede por ello discutir sobre la misma denominación, y debido al uso que hacen de ciertos modelos de acción estratégica se le podría calificar, como han señalado A. Carling, I. Roemer $o_{\text {, }}$ entre nosotros, F. Ovejero, ${ }^{7}$ como "marxismo de la elección racional". Pero en definitiva hablamos de un conjunto de autores, mayoritariamente anglosajones, que, en época posterior al Horecimiento del marxismo de los años sesenta, y en pleno período de lo que se llamó la crisis del marxismo (finales de los setenta), se han dedicado a aplicar las pautas de rigor conceptual heredadas de la filosofía analítica, las consideraciones de la teoría contemporánea de la ciencia y los resultados de las ciencias sociales, en particular los procedentes de la economía neoclásica, al tratamiento de problemas tradicionalmente abordados por la teoría social marxista.

Sin embargo, tampoco debemos olvidar que su autodenominación como "marxistas analíticos" tiene la virtud, en estas épocas de mercadotecnia, de un buen rotulo para una personal campaña publicitaria; además resulta muchas veces ingenua la pretensión de los marxistas analíticos de presentarse como quienes inauguran una problemática filosófica completamente nucva, cuando sucede en realidad que la tensión existente entre modelos explicati- 
vos, utilizados o rechazados, forma parte de la misma historia del pensamiento marxista y de otras tradiciones filosóficas occidentales. ${ }^{8}$

Es conveniente no olvidar que el calificativo de analítico en un libro como Analytical Foundations of Marxian Economics, de Roemer (1981), tiene poco que ver con la filosofía analítica; se trataba alli más bien del uso de las herramientas del análisis matemático para realizar una aproximación formal a la economía marxiana, continuando los antecedentes importantes de M. Morishima, N. Okishio y, en general, siguiendo la tradición sraffiana.?

Algunos análisis superficiales consideran exclusivamente la influencia de la filosofía analítica sobre el marxismo analítico, y con ello se disponen a seguir a éste en sus peores aspectos, en Ios más conservadores, académicos $\mathrm{y}$, particularmente, escolásticos. Sin embargo, otros autores, entre ellos E.M. Wood y F. Ovejero, han sabido ver otro tipo de conexiones y convergencias inesperadas; por ejemplo, han analizado la conexión con la orientación estructuralista del pensamiento marxista francés, relación que benévolamente se podría explicar utilizando la propuesta hecha por M. Sacristán de ver como herencia hegeliana la noción de sistema utilizada por Marx; pero, en mi opinión, tal inesperada conexión tiene que ver con los peores aspectos dogmáticos del marxismo cientificista.

En todo caso vamos a fijarnos en si este neomarxismo puede ser un buen punto de partida para la reflexión sobre problemas del presente social, para el debate en ciencias sociales y sobre cuestiones de método en ellas. Asi que no estará de más recordar, aunque en nuestro caso no lo hagamos con afán descalificador, la opinión expresada por E.M. Wood ${ }^{10}$ sobre que las técnicas de investigación de la elección racional tienen uno de sus orígenes en el renacimiento del pensamiento de la derecha conservadora; si lo peculiar de estos marxistas estuviese sólo en el uso de esas técnicas, desde luego con ello no se les podría caracterizar como grupo diferenciado entre los científicos sociales.

Un primer rasgo de este marxismo, si aceptamos la opinión de Roemer, es su compromiso con la abstracción, la teorización y las exigencias formales de la construcción teórica. Hay pocas dudas sobre que el marxismo se deje caracterizar principalmente por una determinada concepción de la historia; sin embargo, los marxistas analíticos insisten en la necesidad de analizar los productos intelectuales con cierta independencia de su génesis histórico-ideologica. Esa actitud ya les ha reportado alguna que otra crítica que les considera "marxistas de cátedra»." 1

El compromiso con la abstracción es consecuencia de otro rasgo característico de este particular marxismo: la investigación de fundamentos para la teoria social $y$, por ello mismo, no dar por resueltas una serie de cuestiones que el marxismo tradicional evitaba plantearse o que, simplemente, consideraba irrelevantes (entre otras razones por la adopción de una filosofía de la historia escatológico-progresista)..$^{12}$

Cuestiones como las siguientes: ¿por qué es injusta la explotación, entendida como transferencia de plus-trabajo?, ¿es la igualdad un objetivo de la ética marxista?, interesa el socialismo a los trabajadores de las sociedades del capitalismo modemo? ¿por qué y cómo emergen las clases como importantes actores colectivos?, ¿por qué se produce la acción colectiva a pesar de los beneficios obtenidos por quien se comporta como polizón (free-rider)?, ${ }^{13}$ ien qué particular sentido no es libre el prolctariado bajo el capitalismo?, ¿por 
qué es superior el socialismo al capitalismo y en qué aspectos?, son preguntas todas ellas que conforman, utilizando el término empleado por Roemer, un conjunto algo herético, ya que su análisis resulta bastante extraño para el marxismo tradicional pero, sin embargo, corresponden a los trabajos básicos de J. Elster, Allen Wood, A. Przeworski, Gerald Cohen, John Roemer, van Parijs y otros autores que podriamos incluir en la rúbrica del marxismo analítico. La simple formulación de muchas de estas preguntas define un nuevo campo de problemas en la ciencia social de inspiración marxista, asunto que adquiere un interés especial desde el punto de vista de la filosofía de la ciencia; perspectiva que no es precisamente secundaria para nuestros autores.

Desde el punto de vista metacientífico, uno de los temas sobre el que han llamado la atención los marxistas analíticos es el referido a la explicación; y, en buena medida, constituye la problemálica principal de un trabajo que puede considerarse pionero de esta comiente el libro de G. Cohen (1976): Karl Marx's Theory of History, a defence. ${ }^{14}$ En ese libro Cohen dedica todo un capítulo al tema de la explicación funcional y lo hace según el mejor estilo de la filosofia analítica, algo realmente infrecuente entre los marxistas.

El tema de la explicación ha sido planteado también en forma minuciosa por Jon Elster $\mathrm{y}$ ha formado parte de un debate intragrupal, producido particularmente entre Elster y Cohen. ${ }^{15} \mathrm{El}$ análisis de la forma de la explicación funcional tiene para nosotros un interés añadido porque en la ciencia económica tanto la perspectiva marxista cuanto la neoclásica comparten ciertos vicios del razonamiento teleológico. Los economistas neoclásicos suelen adoptar una actitud de confianza absoluta ante las consecuencias de las conductas individuales no coordinadas cuando éstas se producen en el ámbito del mercado; los marxistas, aunque no participen de esa actitud esperanzada y teleológica sobre las consecuencias de la actividad de mercado y de la conducta individual, sin embargo, consideran, si se quiere en un marco más amplio, que la historia avanza hacia sociedades cada vez mejores como consecuencia de la teoría del materialismo histónico; todo ello a pesar de que algunos propongan múltiples y diversos matices sobre la plurilinealidad del desarrollo.

El uso del patrón de explicación funcional por parte de los marxistas -y por Marx - está unido, según Elster, a otro compromiso metodológico: la adopción del holismo o colectivismo metodológico. Así ocurre, por ejenplo, con la adopción del "capital» o de la "humanidad" como sujetos colectivos previos, que tienen preferencia sobre los individuos en el orden explicativo. «No lo saben pero lo hacen, de acuerdo con las leyes del capital." Sin duda, los componentes holistas y los componentes finalistas de la filosofía de la bistoria marxiana son los que conducen a la adopción del patrón de explicación funcional. ${ }^{16}$

En cualquier caso debemos ser precisos y observar que no toda explicación funcional adopta el compromiso del holismo metodológico, aunque normalmente se hayan entendido las críticas al funcionalismo como defensas del individualismo metodológico. Por ejemplo, el mismo trabajo de Cohen puede ser caracterizado como funcionalismo con individualismo metodologico, un matiz entre otros muchos que tampoco discieme E.M. Wood en el artículo ya referido sobre el marxismo de la elección racional.

La reflexión sobre las diversas formas de explicación y la adopción de cierto compromiso con el individualis- 
mo metodológico conforman la tendencia principal entre los marxistas analíticos; ocurre así porque la búsqueda de microfundamentos ha conducido de manera natural a una revisión de las discusiones de los años cincuenta sobre el individualismo metodológico $\mathrm{y}$, tal reconsideración metodológica (todo lo matizada que se quiera), ha producido como subproducto no intencional la adopción del instrumental teórico de la teoría de la decisión racional y de las técnicas de la economía neoclásica para replantearse temas centrales -económicos y políticos- de la tradición marxista. Por supuesto que no ha sido sólo la reconsideración metodológica la que ha conducido al uso de esas nuevas técnicas; también ha contribuido a ello que algunos sean economistas

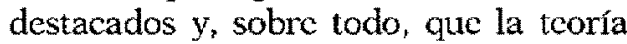
de la elección racional estaba adquiriendo una fuerte expansión en la ciencia social académica.

Entre estos marxistas ha sido Jon Elster, desde los años de su publicación de Logic and Society (1978) pasando por Explaining Technical Change (1983) hasta The Cement of Society (1989), quien ha trabajado con mayor detalle sobre las cuestiones generales de teoría social y sobre filosofía de la ciencia social.

Por supuesto que la adopción del individualísmo metodológico por parte de estos autores no es una posición ingenua que olvide la intensa discusión de otras épocas entre el individualismo y el holismo metodológico, y que constituyó durante mucho tiempo uno de los tópicos centrales en filosofía de la ciencia social. Senfalemos que la posición es muy matizada pero observemos, también, que aunque desde el holismo se hayan hecho algunas corrocciones llegándose a hablar, por ejemplo, de holismo concesivo, ${ }^{17}$ aún así, entre el holismo concesivo y el indivi- dualismo metodológico no ingenus, continuan existiendo diferencias fundamentales de perspectiva con respecto a la explicación en ciencia social.

Ahora bien, si se puede hablar del marxismo de la elección racional es porque, entre otros, Elster, Roemer y Przeworski han reflexionado sobre la teoría estándar de la racionalidad, y, sobre su posible interés para abordar ciertos temas de la acción política que estaban poco elaborados en el maxxismo tradicional. Han tratado de analizar cierto tipo de constricciones no objetivas que pueden ser resultado de limitaciones intencionales puestas por el mismo individuo, y que son además parte de cierta clase más general de restricciones a la acción; un tipo de restricciones que resulta indispensable considerar ya que no pueden evitarse, pues a veces adquieren un papel de determinantes causales de la acción, $y$, en general, tendrían que ver con la conocida apreciación marxista (gramsciana) de que siempre se es conformista de algún conformismo.

Por nucstra parte, señalemos que en la definición misma de individuo debemos asumir que la actividad social, y los procesos de constricción de información, tienen cierto papel constitutivo de dicha entidad individual. Desde luego que se acepta la presencia de procesos materiales objetivos, no sólo procesos naturales sino otros que bien podríamos llamar sociales, que nos limitan la información, que pueden ser asimilados a los procesos de producción de información en el sentido de praducción de posibilidades de información; pero, como la información empieza a ser relevante cuando puede ser utilizada, puesto que por mucha variedad potencial existente si no puede utilizarse es como si no hubiese variedad de ningún tipo, por tanto, sera conveniente considerar la posibilidad de ex- 
plicar intencionalmente tanto la acción individual cuanto otros diversos resultados de las acciones producidas «colectivamente».

Sobre la conformación de la individualidad ha hecho aportaciones de mucho interés Arnartya Sen, de quien recientemente ha sido traducido el trabajo Sobre ética y economta:; ${ }^{18}$ las elaboraciones de Sen generalmente han sido tenidas en cuenta por los marxistas analíticos, y aqui nos apoyamos principalmente en lo que fueron sus conferencias Dewey de 1984, publicadas con el título genérico: Wellbeitng, freedom and agency. ${ }^{19}$ En esos artículos Sen formula con precisión la indispensabilidad de las constricciones informativas presupuestas por todo compromiso o principio moral; tales ligaduras informacionales son las que permiten hablar con coherencia desde determinada posición moral, ${ }^{20}$

Volver sobre el ámbito de la explicación intencional puede ser un camino interesante para la reconstrucción de las ciencias sociales, también para cierto tipo de reflexiones que cabría llamar de filosofía moral, y no es extraño que temas referidos a la teoría ética y a problemas de justicia sean línea dominante en el trabajo reciente de los marxistas analíticos. Además de la noción misma de explicación intencional resulta también imprescindible delimitar el supuesto de racionalidad que está a la base de una posible interpretaciôn de la acción eficaz $\mathrm{y}$ de una acción justa. No parece que estemos dispuestos $\sin$ más a aceptar que la conducta habitual pueda ser analizada como cierto tipo de comportamiento óptimamente racional, pues no se trata solo de que en algunos casos se produzea una aplicación práctica inadecuada de las normas de racionalidad sino, tambiên, porque es difícil suponer que seamos capaces de hacer algo diferente a ejercitar una racionalidad mínima; noción ésta que además debemos empezar por definir.

Seguramente podemos hablar de poco más que de una racionalidad imperfecta para referimos a cómo en la conformación de nuestras creencias y de nuestros fines pueden estar actuando fenómenos causales infra y supraintencionales; rasgos que hacen inviable la adopción de una racionalidad restringida exclusivamente a la relación medios-fines. Este conjunto de temas ha sido analizado con mucho detalle por J. Elster, para fundamentar su defensa de la explicación intencional como elemento más característico de las ciencias sociales, $y$, para mostrar que no basta con caracterizar la racionalidad como eficacia de la acción, como adopción de medios adecuados para fines deseados. Elster ha presentado esos límites de la racionalidad señalando un conjunto de factores que actuan a espaldas de los actores, a veces desde el interior mismo de ellos, y que debemos estudiar para poder adoptar algún tipo de decisión en el ámbito de nuestra acción, especialmente en aquellos aspectos en los que parece necesaría una valoración moral.

En definitiva, la racionalidad imperfecta es una propuesta que tiene en cuenta los posibles éxitos de lo que se ha llamado ingeniería social (fragmentaria); sin embargo, y a pesar de la ausencia de grandes modelos sobre la sociedad futura, considera que es posible $y$ a veces inevitable plantearse transformaciones globales de conjunto de un sistema si queremos superar las claras ineficiencias del presente. $\mathrm{O}$ bien, en el caso de no plantearse tales proyectos globales, cabe la posibilidad de adoptar nuestras decisiones de acuerdo con determinadas convicciones, a pesar de nuestra inevitable ignorancia sobre las consecuencias de nuestra acción.

Así Elster ha estudiado situaciones 
en las que no podemos asignar probabilidades a los estados futuros, ni tampoco conocemos esos estados futuros del sistema a los que podríamos querer dirigimos. En estos casos, de incertidumbre radical, aparece la relevancia del estudio y el análisis de la intencionalidad, qué parte de éstas puede cubrir la acción racional y qué conjunto de factores causales están influyendo en nuestra conducta.

Al mismo tiempo interesa señalar que la constricción fundamental no reside en exclusiva en el tipo de información disponible, sino que se encuentra en el usuario de esa información, está en el elemento subjetivo de la información, y se configura en el receptor que llamamos individuo. Noción de individuo que siendo central para el análisis moral, es importante también para el análisis político; aunque en uno y otro caso el tipo de información disponible o incorporable sea diferente. La actitud básica en ambos campos consiste en la adopción del individualismo metodológico como principio elemental básico de las ciencias sociales, un postulado sin el cual parece absurdo hacer reflexión social.

La revitalización del individualismo metodológico, especialmente por parte de J. Elster y J. Roemer, va unida, como hemos intentado mostrar, a la intención explicita de recuperar algunos de los principios básicos de la sociologia de la acción, por ejemplo, aquel que aconseja analizar el cambio social como resultado de un conjunto de acciones individuales. Elster entiende por individualismo metodológico la hipótesis de que todos los fenómenos sociales - su estructura y su cambio- son en principio explicables en una forma que incorpora sólo a los individuos, a sus propiedades, relaciones, objetivos, creencias y acciones.

Será conveniente señalar algunas de las matizaciones que, para defenderse de las críticas surgidas en las discusiones de los años cincuenta entre holistas $e$ individualistas, hace Elster para su propuesta individualista metodológica.

En primer lugar, la posición no presupone ni la racionalidad ni la acción exclusivamente egoista; sólo hay una cierta presunción de estos rasgos comportamentales desde el punto de vista metodológico, pero no se hace referencia a rasgos de la naturaleza humana. Un segundo aspecto es que el individualismo metodológico se sostiene sólo en contextos extensionales; cuando una entidad agregada aparece en un contexto intensional no es reductible a nivel inferior, v.g.: la gente puede tener creencias sobre entidades «supraindividuales" que no serian reductibles a creencias sobre individuos. Así Elster analiza el enunciado: "los capitalistas temen a la clase obrera", que no podría reducirse a enunciados que hablen sobre los sentimientos de los capitalistas respecto a trabajadores individuales. Por contra, podríamos decir que un enumciado como: «El beneficio capitalista es el resultado de la explotación a la que está sometida la clase obreras, se puede intentar reducir a un enunciado complejo que muestre los mecanismos mediante los cuales los trabajadores incividuales resultan explotados en el sistema industrial por parte de los capitalistas.

En tercer lugar debemos observar que en la descripción precisa de un individuo pueden incorporarse referencias esenciales a otros, ya que muchas de sus características (v.g., ser explotado, ser poderoso) son inherentemente relacionales.

Elster señala además una cuarta cautela: la posibilidad de la reducción no debe cegarnos ante los peligros de reduccionismos prematuros; asi ocumre que muchos intentos de explicar fenó- 
menos sociales complejos en términos de motivaciones, creencias individuales y procesos cognitivos individuales producen con frecuencia explicaciones arbitrarias, estériles, o que llegan por otros caminos a la posición ingenua dc quien aspiraba a que el anâlisis químico de la sopa supiese a sopa. Elster mismo ha estudiado tales dificultades, y creo que hasta las ha experimentado, en el problema de la búsqueda de microfundamentos para la acción colectiva. Su posición es que aun cuando en esos casos puede parecer conveniente mantener las explicaciones tipo caja negra, no debemos olvidar que la adoptamos a falta de otra explicación mejor. En tal sentido el holismo metodológico puede ser una necesidad temporal, pero nunca un desiderátum.

Quizá valga la pena señalar, aunque sin discutirlo, que el individualismo metodológico no hace referencia a la forma de evaluar los fenómenos sociales, sino al modo de intentar explicarlos; esto es tanto como decir que debemos mantener clara la diferencia entre individualismo ético e individualismo metodológico. Por ejemplo, se puede observar que Marx resulta más consistente en la adopción del individualismo ético (la principal atracción del comunismo es que hará posible la completa realización de los individuos en libertad) que en la pretensión de explicar en términos de las acciones de los individuos los procesos orientados al logro de la "fase" comunista de la sociedad.

Si pretendiesemos identificar compromisos metodológicos adoptados por Marx, sin duda el apoyo textual estaria con el rechazo del individualismo metodológico y, a la vez, con la aceptación del patrón de explicación funcional.

Para nosotros lo importante es que, según los marxistas de la elección racional, el individuo aparece "metodológicamente» como responsable de la se- lección de la información. Para mostrar la relevancia de la información que seleccionamos, y el papel que debemos dar al individuo, a sus mecanismos y compromisos seleccionadores de información, valdría la pena analizar algunas posiciones morales cercanas entre sí; por ejemplo, el utilitarismo de acto u ocasional y el utilitarismo de norma o regla. ${ }^{21}$

Por ese camino volvemos a encontramos con las propuestas de A. Sen, quien ha presentado y resumido su posición recientemente, con ocasión de la recepción del premio internacional Giovanni Agnelli, (discurso publicado en el New York Review of Books del 14 de junio de 1990 , pp. 49-54, bajo el titulo "Individual Freedom as a Social Commitment»). La tesis de Sen es que "El individuo retorna como logro social, como conquista social», "La libertad individual no es sólo un valor social central sino que es también inevitablemente un producto social»; ese camino indicado por A. Sen puede servir para una consideración interesante de los problemas sociales del presente, y creo que aquí vale la pena que recordemos a Kolakowski: «en este punto comparto el principio de Kierkegaard: la responsabilidad colectiva es una ficción, si pretende ser algo distinto que la suma -la suma exacta - de las responsabilidades particulares. Si una sociedad cualquiera, y sólo ella, es responsable para algo, pero no algún particular, la responsabilidad pesa simplemente sobre el universal, es decir sobre nadie, ${ }^{22}$ Pero no podemos considerar responsable a quien no es agente; no creo que el pecado de omisión no consciente, $\mathbf{u}$ omisión no intencional, sea un caso relevante. De ahí la importancia del análisis de la conformación autónoma de la individualidad y de la valoración de las capacidades, que permite o facilita desarrollar una sociedad, 
con preferencia sobrc los aspectos cuantitativos del bienestar. Este camino seguido por A. Sen nos parece muy relevante para una evaluación crítica de los sistemas sociales.

Pero veamos algunas primeras dificultades que presenta el marxismo analítico. Una primera limitación hace referencia a lo inadecuado de su tratamiento de los conceptos teóricos y del papel jugado por ellos en el seno de las teorias científicas; como consecuencia adoptan una excesiva dependencia de las concepciones verificacionistas de las teorias cientificas con lo que se enredan en discusiones ontológicas de las que por desgracia bien lleno está ya el marxismo. ${ }^{23}$ Un buen ejemplo lo suministra la ambigüedad de las posiciones que adoptan con respecto a la teoría del valor-trabajo. Una teoría que si bien parece derruida por la reconstrucción "neoclásica» de Roemer, siguiendo los pasos de Morishima, aparece aún ante los ojos de Elster como un mal menor, como una posible via interpretativa a falta de otra mejor. Más bien parece que no saben a qué carta quedarse. Creo que se necesita una mayor precisión sobre el uso de modelos en las ciencias sociales y no temer a la dificultad de ausencia de realismo en las teorias. Sin duda que los modelos construidos a partir de la teoria del valortrabajo tienen un alto rendimiento práctico y, además, la noción «valor» tiene tanta legitimidad en el campo de las teorías económicas, como la que pueda tener el término teórico "fuerza" en la mecánica clásica de partículas. ${ }^{24}$

Una segunda limitación del marxismo analítico tiene que ver con su excesiva dependencia de la supuesta simetría entre explicación y predicción. Por ello vale la pena recordar una posición como la de Patrick Suppes, quien, en "Explicando lo impredictible» (1986), con ocasión de un homenaje a Hempel por parte de la revista Erkenttnis, planteaba: "Se ba dicho - y yo estaba entre quienes lo decian- que cualquier teoría de la explicación para ser interesante tendría que hacer buenas predicciones. Si no se conseguian esas buenas predicciones la explicación dificilmente era considerada interesante. Este es otro de los intentos unificadores que ahora considero equivocados... Hemos vuelto a reconocer cuán raros y especiales son los sistemas físicos cuya conducta puede predecirse en detalle. La ingenuidad y las esperanzas de esas épocas tempranas no se sostienen. Para muchos fenómenos en muchos dominios se tienen razones de principio para creer que nunca seremos capaces de movernos de buenas explicaciones a buenas predicciones».

Esta misma idea ha sido planteada por Suppes en otro artículo haciendo referencia a la causalidad-no-markoviana que, aun cuando no sea ahora el momento de comentarla, tiene una importante relación con nuestra discusión, puesto que muchas de las defensas de la explicación funcional, sobre todo si va unida al individualismo metodológico, han supuesto que en las sociedades podrían darse procesos absorbentes de Markov; tal es el caso de van Parijs, y es una línea que ha seguido para su reflexión entre nosotros $L$. Paramio. Se trata en mi opinión, sin embargo, de señalar la importancia de procesos «que no olvidarían su pasado»; en ellos tendriamos que contar con los fenómenos de histéresis que harían posiblemente indispensable el uso de conceptualizaciones no-reductivas para el tratamiento de temas como el de la acción colectiva; no diremos que tales conceptos teóricos serán necesarios temporalmente, por ahora y a falta de otros mejores que consigan reducirlos "observacionalmente», sino que podemos estar ante el caso de una 
auténtica «imposibilidad» predictiva que exija el constante uso de categorias especificas teóricas. Por ejemplo, así puede que ocurra con la noción de individualidad considerada como un constructo social, sin esperanzas de posterior reducción. Aun sienda consciente de lo tentativo de estas propuestas creo que configuran un plano importante de la investigación que está siendo sugerido, por ejemplo, por $\mathrm{R}$. Boudon en sus reconstrucciones de la sociología de Simmel y de las propues. tas metodológicas de Max Weber. ${ }^{25}$ También debemos señalar que ciertas correcciones en las reflexiones metodológicas más recientes de Elster parecen avanzar en este sentido. ${ }^{26}$

Una tercera limitación está conectada con algunos aspectos poco refinados del individualismo metodológico defendido por Elster, y se relaciona con el papel jugado por las instituciones que configuran la situación en la que se encuentra incorporado el individuo que actúa. Este tema ha sido también estudiado por Boudon, pero creo interesante recordar que la posición de Popper planteada hace ya bastante tiempo, por ejemplo en el simposio de Burgos de 1968, es bastante clara al respecto: aLas instituciones no son reducibles a las acciones de los individuos, porque toda acción individual ocurre en una situación y toda situación contiene elementos físicos, elementos institucionales y otros individuos [...] una situación es algo extremadamente complejo [...] la acción del individuo sólo puede analizarse porque el individuo actúa dentro de una situación y ya que las instituciones forman parte de la situación, no podemos reducir instituciones a individuos 0 a acciones individuales". Continuaba Popper preguntándose qué quedaría entonces del individualismo metodológico, y sc contestaba con una importante apreciación que, en definiti- va, es la que mayor rendimiento ha producido en la crítica de Elster al marxismo tradicional. Para Popper, eso que quedaba del individualismo metodológico (y que es precisamente lo que impide la reconciliación con el holismo por muy concesivo que se quiera ser) era que: «Los colectivos no actúan, no tienen intereses, no tienen planes aunque podamos decir por razones de sencillez que actúan, tienen intereses $y$ planes. Quien verdaderamente tiene intereses, planes y actúa es el individuo. Esta es en síntesis la tesis del individualismo metodológicon. 27

No basta con decir que se es precavido respecto a las versiones reduccionistas apresuradas, como hace Elster, sino que debemos considerar elementos metodológicos que no faciliten la tendencia a ese infundado reduccionismo.

En cualquicr caso será conveniente deslindar nuestras críticas de las que han empezado a producirse desde ámbitos de los marxistas fundamentalistas. Podemos citar el ejemplo de Scott Meikle de la Universidad de Glasgow quien, en un número de Inquiry de 1986 dedicado al análisis de Making Sense of Marx de Elster, tras establecer que los componentes del pensamiento de Marx son su teoría de la historia, su teoría del valor y su método dialéctico, aspectos que conjuntamente forman una teoria unificada, termina estableciendo que el libro de Elster no puede ser juzgado sino considerándole un panfleto anti-Marx, antimarxista, bastante agrio e intemperante, dogmático por el sarcasmo y por su constante recurso a los prejuicios antimarxistas de los lectores.

Si uno por un momento se abandonase al mismo estila de irrelevancia argumental podría decir que sostiene cierta esperanza en que la política de transparencia informativa de Gorbachov, la caída de algunos muros y al- 
gún que otro "Gulag", ayude a la intelección de la propuesta de los marxistas analíticos por parte de la tradición fundamentalista.

Con ánimo de concluir, y dejando al margen ese tipo de valoraciones $y$ tentaciones, podemos aún señalar algunas otras deficiencias de importancia. Por un lado, cierto aire de escolástica permea a los autores del marxismo analítico, tanto por no haber superado aún del todo la tendencia exegética sobre la obra de Marx (quizá por la imposibilidad de obviar en la práctica el papel de los fundamentalistas) cuanto por añadir un refuerzo proveniente de la misma filosofia analítica; un refuerzo que no procede del uso de los instrumentos formales del análisis sino de quedarse en el verbalismo del análisis terminológico y considerar conseguida una explicaciôn adecuada tras la mera clasificación de los significados de los términos utilizados. En algunas de las valoraciones de Roemer, de Elster o de Cohen se vislumbra cierta convicción en la capacidad de deslindar ciencia y metafísica mediante algún expediente metodologico que pudiese operar como criterio de demarcación; resonancia que aparece cuando insisten en distinguir entre teoría de la historia y filosofía de la historia.

Por esa razón, en ciertas ocasiones, cuando se acercan a cuestiones de filosofía política parecen recaer en aquella trivialidad de los ejemplos que en otra época criticábamos a los filósofos morales analíticos. Sin duda no será totalmente justa esta crítica si la generalizamos, ya que a veces están tratando de estudiar mecanismos causales intrapersonales relevantes para una teoría general de la acción colectiva; y, por ello, la ejemplificación puede realizarse tanto analizando las dificultades surgidas para seguir un régimen alimentario determinado como en las dificultades cognitivas para percibir el peligro de la existencia de una base militar en nuestro entorno. Pero el aire de superficialidad ejemplificatoria cuando va unido a cierta actitud escolar de análisis de significado resulta bastante llamativa.

En suma, aún pensando que el marxismo analítico es una corriente contemporánea interesante en la reflexión y práctica de las ciencias sociales $y, \sin$ duda, una de las más prometedoras dentro del pensamiento marxista, sin embargo, creo que es conveniente señalar esas debilidades producto de sus residuos exegéticos y de su débil incorporación de la filosofía actual de la ciencia restringiendo su uso a la uconcepción heredada" de las teorias cientificas.

EI estudio de las condiciones bajo las cuales se pueden poner en marcha reformas a gran escala en las sociedades modernas, es una actividad que conecta las pretensiones de las ciencias sociales académicas con algunos objetivos "cientificos" del marxismo. Veamos como aparece ese aspecto praxeológico en el trabajo de alguno de los marxistas analíticos, aunque si hay un aspecto en el que las diferencias son notorias entre ellos, es aquí donde se acentúan pues en definitiva es el ámbito que está más condicionado por los compromisos políticos e institucionales de cada uno.

En las sociedades complejas, industriales, democráticas, los argumentos para la reforma los podríamos clasificar, siguiendo a Elster, ${ }_{r}^{28}$ en argumentos consecuencialistas y argumentos ético-valorativos; según sea porque pensemos que la reforma tiene efectos buenos o deseables, o bien porque por sí misma sea considerada valiosa.

Posiblemente es Elster el que más se aleja de los argumentos consecuencia- 
listas ya que la posibilidad de predecir los efectos globales netos en el equilibrio a largo plazo es algo que parece estar, como dice Elster, a años luz de la situación actual de las ciencias sociales, $y$, por tanto la ingenieria social fragmentaria, mediante el aumento de la planificación y el incremento de los mecanismos de ensayo y error, no ayuda a resolver tal déficit porque su método nos conduce a estimaciones locales, parciales, a corto plazo y a algunos efectos de transición. Hay que distinguir entre establecer una pequeña reforma con carácter general, una gran reforma con carácter local o bien una reforma importante con carácter general. Por ejemplo, probablemente no sería legítimo inferir del comportamiento de las cooperativas obreras en una sociedad capitalista argumentos sobre la eficiencia de un socialismo de mercado, una cuestión que ha sido analizada por Elster utilizando como caso particular el fenómeno cooperativista de Mondragon (Euskadi).

Por otro lado nos encontramos con el contraste entre efectos parciales y efectos netos. Debido a las necesarias cláusulas caeteris paribus que aparecen en las ciencias sociales, estas son muy débiles para actuar de instrumento en la planificación y la reforma; los rasgos que mantenemos constantes pueden ser afectados por los cambios previstos. Por ejemplo, con determinadas motivaciones iniciales, la reforma puede cambiar los comportamientos y, llegado el caso, hasta las mismas motivaciones; este tipo de consideración sobre los cambios motivacionales tiene interés para analizar fases posteriores a transformaciones institucionales. Así se podrian analizar los cambios de comportamiento en nuestro país antes y después de la constitución de 1978: desde luego que cambian la conductas, pero también las motivaciones para defen- der el proceso constitucional; esa es una razón para que nos resulten tan zafios los argumentos de quienes consideran avendaval antidemocráticos toda critica a los procesos políticos que ellos mismos encabezan, y olvidan que pueden darse cambios en las preferencias de los demócratas. Los afectados por la reforma se adaptan estratégicamente (también los llamados «poderes fácticos», que serian un buen caso de análisis), y además un beneficio pensado inicialmente como local y sectorial puede favorecer la tendencia de todos a solicitar la extensión de ese beneficio (pudiendo situarnos como efecto lateral no deseado ante un caso de sfalacia de composiciónm). ${ }^{29}$ De aquí los temores a la "mancha de aceite", a la extensión de las conquistas sociales conseguidas por un sector concreto, pues no se trata sólo de un exclusivo problema de política económica sino del cambio de preferencias. Los efectos no-deseados en ambos polos de los conflictos pueden situarnos en una posición de incertidumbre. En esa encrucijada, los valores puramente técnicos y consecuencialistas de la toma de decisión no pueden ser los que orienten el comportamiento que deseariamos llamar o calificar como "racional».

Además hay otros argumentos fuertes a favor de la incertidumbre. Baste aquí recordar que la eficiencia dinámica de un sistema económico supone una tasa óptima de política de inversión y de innovación técnica, pero el estudio de tal proceso parece señalar que estamos más bien ante procesos de decisión no-racionales (ausencia de intencionalidad y presencia de factores causales de interacción); por consiguiente, no parece que puedan ser anticipidas las consecuencias a largo plazo de las reformas generales y volvemos a estar ante un caso de incertidumbre y no de riesgo. 
Por último añadamos que aun cuando pudiesemos prever un estado accesible y óptimo en el equilibrio social, no deberíamos embarcamos (al menos no embarcar a otros) en tales reformas sin conocer los efectos de transición. Como recuerda Elster, el legado de Marx no sólo incluye el substrato intelectual de creer con certidumbre total que ol advenimiento del comunismo es inevitable, sino tambien el error moral de pensar que ese objetivo justifica todo sacrificio impuesto a las generaciones intermedias. De ahí que algunos autores del llamado marxismo analítico se preocupen cada vez más de esos efectos de transición, de la reversibilidad y la no-acumulación de las reformas y de la necesaria microfundamentación de la teoría social.

Desde luego que este marco problemático no está dirigido a una simple consideración negativa de la ingenieria social entendida como aplicación de los resultados de las ciencias sociales para implantar determinado tipo de reformas; lo único que pretendemos indicar es que la percepción de la justicia de las instituciones $\mathrm{y}$ de las políticas es una condición necesaria fundamental para conseguir situaciones viables a largo plazo en una sociedad democrática.
En definitiva, pretendemos mostrar cómo para la metodologia de las ciencias sociales importa no olvidar las cuestiones relacionadas con la élica o la racionalidad práctica. Una tcoría concreta de la racionalidad que pretenda superar propuestas ingenuas no puede olvidar los trabajos empíricos de los psicológos sociales o de los cognitivistas, pero tampoco debe desechar las consideraciones de los filosofos morales. No parece que la mayor parte de los marxistas analíticos tengan la suficiente sensibilidad ante las propuestas de la filosofía moral y la política, lo que es tanto como decir que proceden a una reflexión muy simplista ( «cientificistaw) ${ }^{30}$ de la acción social al pensar que toda la reflexión del pensamiento filosófico crítico es simple excrecencia filosófica continental.

Aun cuando no sea fácil definir que sea marxismo y resulte compleja la caracterización de lo analítico, y a pesar de todas sus dificultades y limitaciones. la propuesta teónica, la vertiente crítica y el trabajo empírico de estos científicos sociales, que han dado en llamarse marxistas analíticos, merece el respeto debido a quienes hacen un trabajo académico serio.
1. Recogido en J. Elstex; "One. Hundred Years of Marxist Social Sciences en London Review of Books, 16 junio-6 julio 1983, p. 8 -10.

2. I. Roemer (1988): Free to Lose. An introduction to maxist economic philosophy. Londres, Radius, Century Hutchinson Ltd. A este libro, siguiendo el viejo estilo escolastico del marxismo, ya algün discipulo (A. Carling) lo ha llamado *el libro de texto de la teoria marxista contemporánea».

3. Esa es la opinión expresada en Weldes, I: "Marxism and methodological individualism., Theory and Society, 18 (1989), pp. 353-386. El mismo término umarxismo analítico le parece algo pretencioso a Jutta Weldes.

4. En varios lugares, por ejemplo en su Prólogo a Gerard Vilar: Rao e marxism, Barcelona, Eds.
62, 1979: :El marxisme evidentment es troba en crisi, però això és el que el fa apassionadament interessant per als no-marxistes com jo i ens porta a desconfiar daquestes liquidacions totals que tan apressadament emprenen avui tants antics marxistes, vells o nous filsofs\%.

5. Monogafico solre "Analisis y Dialéctica", dirigido por Alfredo Deaño. Revista de Occidente, 138, septiembre 1974 .

6. Roemer, J. (ed.) (1986): Analytical Marxism, Cambridge, Cambridge University Press, 1986, Introducción. (Anunciada traducción en México, Fondo de Culcura Económica, 1990.)

7. Carling, A: «Rational Choice Marxism», New Left Review, 160 (1986). Roemer, J.: eRational Choice Marxism: some issues of method and subs- 
tancen, en J. Roemer (ed.): Analytical Marxism, Cambridge, Cambridge Univ. Press, 1986.

8. Como en parte parece sugerir J. Weldes (op. cit.).

9. Vale la pena recordar que J.M. Vegara (1982): Lecrutas sobre economia politica marxista contemportinea, Barcelona, Antoni Bosch, ya reco. gía un artículo de J.E. Roemer (1977); :Technical Change and the Tendency of the Rate of Profit to Fall, en traducción a cargo de F. Sancho; ahí puede verse claramente la conexión indicada.

10. Ellen Meiksins Wood: «Rational Choice Marxism: Is the Game Worth the Candle? New Left Review, 177, 1989, p. 41-89.

11. Ver el número monográfico sobre éstos temas de la revista nonega Inquiry, octubre 1986.

12. Vid. M. Sacristán: Comunicación a las Jornadas de Ecología y Política en Murcian, Mientras Tanto, 1, Barcelona, 1979.

13. Se han ofrceido diversas traducciones del término por quienes vienten trabajando en la teo. ria de la elección racional, entre otras: gorrón (propuesta por Paulette Dieterlen en sRacionalidad colectiva y marxismo:, México, I.I.F.- UNAM, 1986, ahora recogido en L. Oliv [comp.]: Racionalidad. Ensayos sobre la raciontalidad en etica y politica, ciencia y tecnologia, México, Siglo XXI, 1988) y polizón. Gorrón parece captar mejor cierto componente negativo del no-cooperante.

14. Hay version espanola, G. Cohen: Teoria de la historia de Kal Marx, wha defensa, Madrid. Siglo XXI, 1986.

15. El análisis de la noción de explicación en el marxismo analítico to he tratado con cierto detalle en sobre la noción de explicación en el maxis. mo analítico: un primer balance», recogido en J.F. Álvarez, J. Armero, E. Bustos, P. Casirillo, E. Rada y L. Vega: Variaciones sobre la explicacion. Madrid. UNED, 1990. En algunos pasajes he reformulado aqui partes de aquel irabajo porque, siendo una de las caracteristicas del marxismo analítico su preocupacion por la búsqueda de microfundamentos, debemos dejar claro que el problema de la cxplicación ocupa un lugar central.

16. Para todas estas cuestiones tiene un interes furdamental J. Elster: Making sense of Maxx, Cambridge, Cambridge U. Press, 1985. Seguramente es Elster el autor que, dentro de este grupo de pensadores, más ha reflexionado sobre el conjunto de los problemas metodológicos en las ciencias sociales. Ya se dispone en español de una versión de $\mathrm{J}$. Elster: Explaining Technical Change (1983) (El cambio tecnológico, Rarcelona, Gedisa, 1990), obra en la que se ofrece una presentación general del debate en torno a la explicación. Ahora mismo tendría interés discutir sus trabajos mâs recientes: Solomonic Judgements, Nut and bolts in the social science $y$ The cenent of society, los tres publicados por Cambridge University Press en 1989. He analizado estos úlimos trabajos en "Química social: mecanismos de reacción*, Arbor (en preparación).

17. Susan James (1984): The content of social explanation, Cambridge, Cambridge Lniversity Press, 1984.

18. A. Sen: On Ethics and Economics, Oxford, Basil Blackwell, 1987. (Versión cspanola de A. Conde, Madid, Alianza, 1989.)

19. A. Sen: "Well-being, agency and liberty", $J_{2}$ Dewey Lectures. The Joumal of philosophy, 1986.

20. Obsérvese que esta noción de constricciones informativas o ligaduras informacionales, muestra cierta analogia con la noción de ligaduras interm modélicas utilizada en la concepción estructural de las teorías científicas (Sneed, Moulines, Balzer). Entre los diversos modelos potenciales posibles se establecen ligaduras que vienen a ser la clave para la afirmación empirica de la teoria; aquir sc trata de establecer conscientemente, o de seguir, determinadas ligaduras que constituyen el punto de vista moral adoptado.

Procisamente en el caso de la reconstrucción de ciertos campos de las ciencias sociales mediante la concepcion estructural, en particular en filosofía de la economia, una de las dificultades principales ha surgido por la excesiva vinculación al modelo causalista de explicación y por la construeción de los modelos desde esa óptica causalista.

21. La discusión Harsanyi - A. Sen y la posibilidad de la adopción de una posición no consecuencialista analizada desde el punto de vista de los contenidos informacionales, junto a la consirucción social de la individualidad, son cuestiones que he abordado en: aInformacion y efectos perversosn (ms., inédito, texto de conferencia en Univ, de La Rabida, Huelva, julio 1990).

22. L. Kolakowski: La presencia del mizo, 1990. pâg. 91 .

23. El artículo de J. Weldes ya citado es un buen ejemplo de enredo xontológicos interno a la tradición marxista. Tanta es la tendencia a la discusión ontologica que cada vez que habla de individualismo metodologico para proceder a su críti$\mathrm{Ca}$, en realidad no esta sino hablando de aindividualismo ontológico" (a veces hasta utilizando explícitamente el término).

24. Los problemas de la teoría del valor, la investigación sobre la noción de explotación en el marxismo analítico y mi opinión sobre el programa económico marxista, que se apoya en la teoría del valor-trabajo, como un programa degenerativo aparecen en "Valor y explotación: Apuntes sobre filosofía de la economía marxistaw en número extraordinatio de Arbor (en prensa) compilado por Fda. Quesada.

25. Boudon, R.: La Place du désordre, París, P.U.F. 1984. R. Boudon: whes Problemes de la philosophie de lhistoire de Geog Simmelt une 
théorie de l'objectivité en histoire et dans les sciences socialess, en $\mathrm{G}$. Simmel: Les problenes de la philosophie de thistoire, edicion al cuidado de $\mathrm{R}$. Boudon, París, P.U.F., 1984.

26. Ver nota 16 .

27. Intervención de Popper en debate del Simpasio de Burgos (1968), en Ensayos de Fitosofta de la Ciencia, Madrid, Tecnos, 1970.

28. En lo que sigue nos fijannos en los trabajos de Elster, "La posibilidad de una política racionals, recogido en $\mathrm{L}$ olive (comp.) (op. cit.), pp. 132-176, traducción de Adriana Sandoval, y su comentario a las propuestas de van Parijs y van der Veen de transición capitalista al comunismo mediante el salario uriversal garantizado («universil grant $x$ ) recogido en Theory and Soctety, 15 (1986). Algunos de estos últimos materiales los conoci gracias a Fdo. Aguiar quien realiza en la UNED un trabajo de doctorado sobre elección social.

29. Que para todos sea posible ser atendido en la sanidad pública no significa que sea posible atender a todos en esa red sanitaria. Para detalles sobre esta noción, vêase Elster: Logic and Society. 1978, y Making sense of Marx, p. 44, donde se relaciona este tema con la noción de contradicción social y algunos aspectos que considera recuperables del razonar dialéctico.

30. Témino que hablando de marxismo nos hace recordar, aunque no se refiera al tema aquí estudiado. el muy recomendable libro de Fco. Fdez Buey: Contribucion a la critica del marismo cientificista, Barcelona, Edicions Universitat de Barcelona, 1984.

\section{Del análisis a la pragmática. Las nuevas ínfulas de un viejo estilo}

\section{JULIO SEOANE}

El primer objetivo de Rorty es la filosolía analítica. No creo que haga falta decir que esta filosofía ha conformado el pensamiento americano desde los años treinta, de tal forma que todo filósofo podría hacer suyo el canto que se deja leer en la introducción a Consequences of Pragmatism «en un principio todos fuimos positivistas\%. Con todo, sería absurdo suponer que este modo de enfrentarse a la filosofia fue uniforme y poco ajeno a disidencias; en verdad, la historia del positivismo es la historia de una forma de pensar que cuanto más profundizaba en sus propuestas y problemas, más tendía a formar nuevas propuestas y problemas que llevaban a elaboraciones cada vez más alejadas del ideal del aanálisis del lenguaje». No ha sido un movimiento estático, sino, muy al contrario, un pensamiento tan dinámico que ha llegado a socavar sus cimientos.
Rorty mismo ha sen̆alado que con la aparición en el panorama filosófico de pensadores como Rawls, Khun o Sellars el positivismo ha culminado $y$ se ha evaporado (la situación de Rawls es reveladora para Rorty, porque es la admisión de un interés por problemas que no se plantean desde la óptica de la filosofía analítica y ni siquiera son propios de la filosofía puesto que Rawls ha interesado a sociólogos, juristas, etc.): «[...] la filosofia analítica culmina en Quine, el último Wittgenstein, Sellars y Davidson, lo cuat es decir que se trasciende y cancela a sí mismam: $y$ esto no es casual puesto que el prejuicio rigorista de este tipo de reflexión filosófica imponía unos márgenes tan estrechos al concepto de racionalidad que, como dice Putnam, no daban cabida ni a la posibilidad de crear una filosofía analítica.

La filosofía y el espejo de la naturaleza 